\title{
Increases in Sex with Same-Sex Partners and Bisexual Identity Across Cohorts of Women (but Not Men)
}

\author{
Paula England, Emma Mishel, and \\ Mónica L. Caudillo \\ New York University
}

\begin{abstract}
We use data from the 2002-2013 National Surveys of Family Growth to examine change across U.S. cohorts born between 1966 and 1995 in whether individuals have had sex with same-sex partners only, or with both men and women, and in whether they have a bisexual or gay identity. Adjusted for age, race/ethnicity, immigrant status, and mother's education, we find increases across cohorts in the proportion of women who report a bisexual identity, who report ever having had sex with both sexes, or who report having had sex with women only. By contrast, we find no cohort trend for men; roughly $5 \%$ of men in every cohort have ever had sex with a man, and the proportion claiming a gay or bisexual attraction changed little. In concluding, we speculate that the gender difference is rooted in a broader pattern of asymmetry in gender change in which departures from traditional gender norms are more acceptable for women than men.
\end{abstract}

Forthcoming in Sociological Science, 2016. Contact first author at pengland@ nyu.edu. 


\section{Increases in Sex with Same-Sex Partners and Bisexual Identity Across Cohorts of Women (but Not Men)}

\section{Paula England, Emma Mishel, and Mónica L. Caudillo}

It is often recognized that norms about gender and sexuality are linked, such that one violates gender norms by identifying as gay or bisexual, or by having sex with a same-sex partner (Pascoe 2007; England 2016). What is less often recognized is a link between trends in the gender and sexuality systems. Gender change has been asymmetric, with women taking on traditionally male activities more than vice versa (England 2010). Consistent with this more general pattern, we will show that the proportion of women who have had sex with a same-sex partner or who identify as bisexual has increased, with no parallel change for men.

Several recent papers, focused mostly on period change in the 1990s and early 2000s, note an upward trend in sex with same-sex partners (Turner et al. 2005; Butler 2005; Twenge et al. 2016). Our study takes a cohort rather than period perspective, examining change across birth cohorts born between 1966 and 1995. We use data from the National Surveys of Family Growth (NSFG) collected between 2002 and 2013. Separately for men and women, we examine change across cohorts in sex with same-sex partners and in gay or bisexual identities, using models that adjust for respondents' age, race, ethnicity, immigrant status, and socioeconomic background (measured with mother's education). We also examine whether trends have been significantly different 
along these dimensions. To foreshadow, we find substantial evidence of increases in women's sexual behavior with same-sex partners, and in women's bisexual identity, but little change for men. We also find that trends differ little by race, ethnicity, immigration status, or socioeconomic background.

\section{PAST RESEARCH ON CHANGE IN SEX WITH SAME-SEX PARTNERS}

Change Across Periods. Several analyses show period changes in sex with samesex partners. Using data from the General Social Survey (hereafter GSS), Anderson and Stall (2002) found an increase from 1-2\% to 3-4\% between 1988 to 2000 in the percent of men who had had sex with a man in the last year. They did not examine trends for women. Turner et al. (2005) also used GSS data, 1988-2002, and found substantial increases in same-sex sexual behavior for women in the 1990s in whether women had sex with a same-sex partner in the last year, the last 5 years, or ever. They found an increase for men only on the measure of same-sex activity in the last year, although it was much smaller than the increase for women; they found no increase for men in same-sex activity in the last 5 years or ever. Twenge et al. (2016) used the GSS data from 1988-2014 and found that the proportion who had at least one same-sex partner since age 18 increased, from 3.6 to $8.7 \%$ for women and from 4.5 to $8.2 \%$ for men. Using $1988-2002$ GSS data, augmented by the 1992 National Health and Social Life Survey, Butler (2005) found increases in the percent of men and women who had sex with a same-sex partner in the previous year across the period, with a faster rate of change for women. A recent analysis by Copen et al. (2016:5), using a subset of the NSFG data we use, found an increase between the 2006-10 and the 2011-13 NSFG surveys in the proportion of women who 
reported same-sex contact, but no change for men. Copen et al. (2016) is the only study of change in sexual orientation; they found an increase in the proportion of both men and women who claimed a bisexual identity across the very short period from 2006-10 to 2011-13.

Taken as a whole, these studies, all of which focused on period trends centered on the 1990s or early 2000s, suggest increases for women in sex with same-sex partners, with mixed findings on whether there is no change or smaller changes for men. ${ }^{1}$

Change Across Cohorts. Research on cohort change in sexualities is sparse. Butler (2005), whose main analysis focused on period change, provided information on change in having had a same-sex partner since age 18 across cohorts born between 1929 and 1982, finding significant increases for women, but not for men. These analyses had no control for age, or other compositional covariates. Likewise, Turner et al. (2005), while focusing on period change, also examined cohort change in the proportions of men and women reporting any same-sex partner since age 18 , finding increases from $1.6 \%$ for the cohort of women born before 1920 to $6.9 \%$ for those born 1970-1984, but no cohort change for men. This cohort analysis was from a model with no covariates, even for age, and thus could be a function of period change or compositional demographic change. Twenge et al. (2016), discussed above, argued that the upward change in having had sex with a same-sex partner identified in their GSS analysis is a period not a cohort effect. However, this conclusion is suspect, given that the techniques they used, proposed by Yang and Land (2013), have been shown via simulation not to identify cohort effects in many cases where they exist (Bell and Jones 2014). Thus, in sum, there are no studies of

\footnotetext{
${ }^{1}$ We focus on the U.S., but note that Johnson et al. (2001:1839), studying the 1990s, found increases for British men and women in same-sex contact during the preceding five years.
} 
change across cohorts in sexual orientation, and the studies examining cohort trends in sex with same sex partners are all flawed by lack of sociodemographic controls, or an inappropriate method of separating cohort from period effects. We will focus on cohort change, controlling for age and other covariates, but make no claims about how much of the net cohort change we observe is a cohort or period "effect."

\section{LIMITATIONS OF PAST RESEARCH AND OUR CONTRIBUTION}

As mentioned above, past research suggests an increase in sex with same-sex partners, but all studies focused on period change, and any cohort analyses they provided were flawed. Thus, one of our contributions is to provide an analysis of cohort change sexual behavior and sexual orientation using models that control for age and other sociodemographic variables.

None of the studies we reviewed distinguished between those who have sex with both men and women and those who have sex only with same-sex partners (either ever, or in a given time period). ${ }^{2}$ Thus, our second contribution is to make this distinction, which is important to understanding the trends among women; as we will show, what has increased is the proportion of women who have had sex with both men and women.

Past research is also limited in that most studies have focused only on behavior. We located no studies examining cohort trends in sexual orientation, so our third contribution is to do so. In sum, our contribution is to provide the first multivariate analysis of cohort change in having sex with same-sex partners only, having sex with same- and other-sex partners, and identifying as bisexual or gay.

\footnotetext{
2 Twenge et al. (2016) do state that most of the period change in having ever had a same-sex partner they document comes from individuals who have had sex with both sexes, but they do not show whether this is true for men and women separately.
} 


\section{DATA AND METHODS}

\section{Data}

We pooled data from the 2002, 2006-2010, and 2011-2013 waves of the National Survey of Family Growth (NSFG). In all of these waves, there was an Audio ComputerAssisted Self-Interview (ACASI) section administered in private that included questions about one's sexual orientation and whether one had same-sex sexual partners. Since this portion of the questionnaire was not face-to-face (the interviewer let the respondent answer on the computer after he/she stepped away), answers about stigmatized behaviors and identities may have less reporting bias. Two recent studies that compared ACASI to standard methods disagree regarding whether it increases reporting of sexual behavior, attraction, or orientation that is not heteronormative. Villarroel et al. (2006) find that a higher proportion of respondents report sexual behavior with or attraction to same-sex partners with ACASI, while Dahlhamer et al. (2014) find no significant difference in reporting a nonheterosexual orientation with ACASI. ${ }^{3}$

\section{Variables}

Dependent Variables: Sexual Behavior. To construct our behavioral dependent variables regarding sexual behavior, we used the questions on same-sex sexual partners in the ACASI section, and the questions on sexual intercourse with other-sex partners in the main questionnaires to identify whether each respondent had: 1) had sex with otherand same-sex partners, or 2) had sex only with same-sex partners. (Those not in the

\footnotetext{
${ }^{3}$ Two qualitative studies in the U.K. also suggest, albeit indirectly, that ACASI would reduce underreporting. Some gay or bisexual respondents reported to Betts (2009) that they would more likely reveal that they were not heterosexual if a survey used a method where neither the interviewer nor people in the household could hear or see their response. Similarly, some gay and bisexual participants in the study by Ellison and Gunstone (2009) said that they would reveal their sexual orientation in an online survey but would say they were heterosexual if asked by an interviewer.
} 
preceding categories of interest had had sex only with other-sex partners, or with no one.) Respondents were asked questions that put them in these categories with respect to their sexual behavior ever, and their behavior in the last 12 months.

The specific questions we used from the ACASI section are: "Thinking about your entire life, how many [same-] sex partners have you had?" and "Thinking about the last 12 months, how many [same-] sex partners have you had?" Women were asked these questions if they stated yes to a prior question about whether they had ever had "sexual experience of any kind with another woman" or yes to one of two prior questions about whether they had ever given or received oral sex to/from a woman. (In 2002 only, the oral sex questions were not asked, so women were asked how many same-sex partners they have had, last year or ever, only if they answered yes to ever having had sexual experience with a woman.) Men were asked their number of male sexual partners, ever or last year, only if they answered yes to either of two previous questions regarding whether they had ever had oral or anal sex with a man. Respondents who did not get asked the questions about number of same-sex partners because of their negative responses to the prior questions were assumed to have had no same-sex partners. To measure other-sex sexual activity, we relied on the NSFG official recodes for number of other-sex sexual partners with whom respondents had intercourse ever, and in the last 12 months, based on information provided in face-to-face interviews using the survey's main questionnaires. Using the combination of these variables allowed us to ascertain whether each respondent had ever had sex with at least one man and woman, or only with one or more women, or only with one or more men. This was our main behavioral dependent variable. In a supplementary analysis, we also used these measures of behavior for the last year. 
One potential problem in comparing women's and men's levels of sex with samesex partners is that the different screening questions used to path men and women into questions about same-sex partnerships appear at first glance to have created a higher bar for men than for women to be seen as having had a same-sex partner. That is, men weren't asked how many male sexual partners they had had (and thus were assumed to have had none) unless they said they had oral or anal sex with a man, whereas women could be classified as having had sex with a woman if they said they had had any sexual experience with a woman, even if they did not report having had oral sex with a woman. Recent attention to the prevalence of women kissing women on dance floors and at parties (Rupp et al. 2014; Hamilton 2007) raises the question of whether women reporting sexual experience with women are referring to experiences such as these or to more private sexual contact involving genitals. In analyses not shown we ascertained that $91 \%$ of women of age 18-45 who said they had sex with a woman last year (regardless of whether they also said they had sex with a man) also reported that they had ever had oral sex with a woman, as did $88 \%$ of (the overlapping group of) women who reported having sex with both men and women last year. ${ }^{4}$ This suggests that the vast majority of those who say they have had a female sexual partner have had private sexual experiences with women beyond kissing. We are thus relatively unconcerned that the measures artifactually create a higher bar for men than women reporting on sexual behavior.

Dependent Variables: Identity and Attraction. To assess identity, we used a question that asked respondents whether they see themselves as "heterosexual or

\footnotetext{
${ }^{4}$ By contrast, only $71 \%$ of women $18-45$ years of age who called themselves bisexual report ever having had oral sex with a woman. Indeed, Brown and England (2016) found that $23 \%$ of bisexual women have never had sex with a woman (16\% have had only male partners, and $7 \%$ no partners of either sex).
} 
straight," "homosexual, gay, or lesbian," or "bisexual." 5 Whether we are referring to men or women, we will use the term "gay" (as opposed to "lesbian") for brevity and to facilitate comparing analyses across genders. One complication is that in the 2002 wave and part of the 2006-2010 wave (through June 2008), respondents were given the option of choosing "something else" to describe their sexual orientation; we treated respondents who gave this response as in the reference category (with heterosexuals).

In supplemental analyses we also use current attraction, a 5-point scale with categories for only attracted to females, mostly attracted to females, equally attracted to males and females, mostly attracted to males, and only attracted to males (with gender order reversed for female respondents). We treated respondents who chose "not sure" as having a missing value, so they were eliminated from the analysis. We recoded the categories into heterosexual attraction (only attracted to the other sex), bisexual attraction (attracted mostly to either sex, or equally to both), and gay attraction (attracted only to one's own sex).

Independent Variables. Our main independent variable of interest is respondent's birth cohort, represented by indicator variables. The categories containing enough respondents for analys is are 1966-74, 1975-79, 1980-84, and 1985-95; we eliminated respondents born between 1957 and 1965. We do not enter period into our main models, but we do employ detailed controls for age-indicator variables for each single year of age at survey. We will focus on cohort change, but make no claims about

\footnotetext{
5 The exact words used for the "gay" option varied by sex and year. In 2002, the option was "homosexual" for both men and women. In 2006 and later, the "gay" option for women was "homosexual, gay, or lesbian" while for men it was "homosexual or gay."
} 
cohort versus period "effects" given the difficulty of distinguishing them (Bell and Jones 2014).

Control variables include indicator variables for the following race/ethnic groups: Non-Hispanic White (hereafter white), Non-Hispanic Black (hereafter black), Hispanic, and Other. We also control for immigration status (=1 if not born in the US), and an interaction for Hispanic X Immigrant that preliminary analysis showed to be needed. The other control we used was respondent's mother's education, represented by indicator variables for completing Less than High School, High School (including those with some college but not a Bachelor's degree), or a Bachelor's degree or higher. These variables enter our main models to control for compositional change along these dimensions, removing its effects from our estimates of cohort change in sexual outcomes. In separate analyses, these variables are also used to examine whether the gender-specific trends in sexual outcomes that we identify vary along these dimensions.

Means on all variables, separately for men and women, are in Table 1. All of our analyses incorporate survey weights corresponding to the relevant data collection years.

\section{Models}

Main Models. We estimated a series of logistic regressions. Each regression is comprised of the cohort indicators as the primary independent variables, as well as all the control variables discussed above. Our goal is to get point estimates of the amount of change in each dependent variable between cohorts. The controls for age are intended to help us distinguish between cohort and life cycle differences, given that the cohorts differ in the age distribution of respondents in the survey. Because of the familiar age-periodcohort identification problem, we do not put the survey year (period) in our main models, 
and thus the cohort trends that we estimate may contain a combination of cohort and period effects. We control for race, ethnicity, immigration status, and mother's education because these variables may affect sexual behavior or identity, and, thus, compositional change across birth cohorts might create cohort effects. For example, we will show a much lower rate of same-sex sexual behavior by Hispanic immigrants than other groups; given this, and the fact that the proportion of successive cohorts made up of Hispanic immigrants increased (results not shown), failure to control for this compositional factor would, all else equal, lead to an underestimate of any increase (or overestimate of any decrease) in sex with same-sex partners. We seek to identify change across cohorts which is not driven merely by compositional changes in our measured control variables, but which is driven by changing behavior within these groups; the controls accomplish this.

All models are estimated separately for men and women, allowing us to examine whether trends differ by gender. For each gender, we estimate logistic regression models that predict the following dependent variables:

Model 1: Has had male and female sexual partners ever

Model 2: Has had only same-sex sexual partners ever

Each of these has a reference category that contains all categories other than the one listed. Thus, the reference categories for Models 1 and 2 are overlapping such that those who have had no sexual partners or only those of the other sex are in the reference category for both models, while those with both sexes as partners are in the reference category only for Model 2 and those with only same-sex partners are in the reference category only for Model 1. 
To examine cohort change in sexual orientation (identity), we estimate two logistic regression models that predict dependent variables measuring the sexual orientation the respondent identifies with:

Model 3: Bisexual

Model 4: Gay

Each of these has a reference category that includes the other, and also includes those who answered heterosexual (and, in the years when it was an option, something else).

Supplementary Analyses. In an analysis discussed but for which full regression results are not presented, we estimated models parallel to 1 and 2 , regarding sex with same- and other sex partners, or same-sex partners only, but referring to partners in the last year (rather than ever). In another supplementary analysis discussed but not displayed in our regression tables, we ran models parallel to 3) and 4) but taking bisexual and gay attraction (as specified above) as the dependent variables, rather than identifying as bisexual or gay.

We also undertake supplementary analyses to examine whether cohort trends we identify in any of our main models discussed above differ by race, ethnicity, or nativity. To do this, we estimate separate models for whites, blacks, U.S.-born Hispanics, Hispanic immigrants, and others. We then examine the significance of differences between cohort coefficients in the models for whites and each other group. We discuss these findings, but they are not shown in our regression tables. Analogously, to see if those from different socioeconomic backgrounds experienced distinct trends, we estimate separate models for each group by mother's education, and examine the significance of differences between 
cohort coefficients for those whose mothers were at least college graduates and each other group.

Predicted Probabilities. From all of our models, we calculated predicted probabilities of observing the sexual behaviors, identities, or attractions of interest across cohorts. We used the "Margins" procedure in STATA, thus using an average marginal effects approach which assumes the control variables to have the distribution observed for the whole (male or female) sample in each cohort.

Sensitivity Tests. These tests are described, along with their results, in an appendix, as none of them changed the substantive conclusions from our main analyses.

\section{RESULTS: CHANGES IN WOMEN'S BEHAVIOR AND IDENTITY Overall Trends}

Table 2 presents our main regression analyses for women, where cohort change is estimated under controls as detailed above. Model 1 reveals the cohort change in whether women have had sexual partners of both sexes (ever), while Model 2 does the same for having had only women as partners. Each successive cohort shows a significant elevation from the reference birth cohort (1966-74), and increases are monotonic. Model 3 also shows significant monotonic upward trends in identifying as bisexual. Model 4 shows some increase in identifying as gay in the last two cohorts, but not enough to be statistically significant.

We can see the levels of these behaviors and identities and the magnitude of change more clearly in Table 3, containing predicted probabilities for each cohort, calculated from the models in Table 2 and some of our supplementary models on related 
outcomes. Table 3 shows that the predicted percent of women who had ever had sex with both men and women increased from $10.3 \%$ in the $1966-74$ birth cohort, to $19.7 \%$ in the 1985-95 cohort. The percent of women who had ever had sex with only female partners, always very small, nonetheless rose significantly from $0.2 \%$ to $1.5 \%$ from the first to last birth cohort. Having had partners of both sexes, as well as having had only female partners in the last year also increased, but the regressions (not shown) don't show these increases to be significant. Bisexual identity increased significantly from $2.7 \%$ to $7.2 \%$ across the four cohorts, while bisexual attraction increased significantly from $13.8 \%$ to 19.5\%. Gay identity, always much smaller than bisexual identity, did not rise significantly, while gay attraction, also much rarer than bisexual attraction, rose at marginal significance.

In sum, across the four cohorts spanning those born from 1966 to 1995 , we find that having had sex with same-sex partners, bisexual identity, and attraction to same-sex partners grew significantly among women. The increases for behavior and identity can be seen in Figures 1 and 2.

\section{Do Trends Differ by Race, Ethnicity, and Immigrant Status?}

The same general picture of increases across cohorts in sexual experience with same-sex partners applies to all groups of women, as Figures 3 and 4 show. To ascertain this, for the four outcomes in Table 2, we estimated separate regressions for the following groups: Non-Hispanic whites, Non-Hispanic blacks, U.S.-born Hispanics, and Hispanic immigrants. (Regression results not shown. We do not discuss results for the residual category of other races or non-Hispanic immigrants.) Trends in having ever had sex with women only aren't different between whites and any other group besides U.S.-born 
Hispanics, whose rise was significantly faster. Trends in having ever had sex with both sexes are not significantly different between groups, except that increases for black women are much steeper than those for whites, starting at a (non-significantly) lower level in the first cohort and rising to a much higher level. The other difference is that the upward trend in bisexual identity is not seen for Hispanic immigrants. Predicted values show that Hispanics, especially Hispanic immigrants, have the lowest level of any of these behaviors or identities that indicate lack of exclusive heterosexuality. Overall, the conclusion is that all of these groups have upward trends in sex with same-sex partners that are the same as or steeper than those for non-Hispanic whites. Other than Hispanic immigrants, whose bisexual identity did not rise across cohorts, all had a rise in bisexual identity no different than that for white women.

We also examined whether cohort trends vary by socioeconomic background, as measured by mother's education, finding almost no differences. Specifically, there were no significant differences between the cohort effects for these groups of women in having had sex with both sexes, having had sex only with women, or gay identity. The upward cohort effects on bisexual identity were larger for the group with the lowest mother's education, and one of these differences (the elevation between the first and second of the four cohorts) was significant. Overall, these monotonic upward cohort trends occurred among women of all socioeconomic backgrounds. Thus, it is certainly incorrect to say that the rise of nonheterosexual behaviors and identities is occurring primarily among socioeconomically privileged white women. Rather, these trends largely transcend race and class, and if anything, some are steeper in less privileged groups. 


\section{RESULTS FOR MEN}

We find no upward trend across cohorts in whether men have had sex with only men, or with both men and women, ever or last year, and no upward trend in either gay or bisexual identity or attraction. The last cohort is never significantly above the first in any of the outcomes (Tables 4 and 5). On two outcomes (partners of both sexes ever and gay identity) the likelihood went down between the first and second cohort. This lack of upward trend is not significantly different for groups of men from varying class backgrounds, defined by their mother's education (results not shown). The lack of trend is true within race/ethnic and nativity groups as well for most outcomes (race-specific regression results not shown, but see Figures 5 and 6 for trends in same-sex sexual behavior and gay or bisexual identity, separately by race). ${ }^{6}$

Our findings differ by gender, not only in the lack of an upward trend for men, but also in the lower baseline levels of departures from exclusive heterosexuality for men, as can be seen in Figures 1 and 2. As Table 5, giving predicted probabilities, shows, in every cohort, between $3.5 \%$ and $4.8 \%$ of men have ever had both sexes as partners, and between $0.8 \%$ and $1.5 \%$ had had only same-sex partners, with no significant upward trend in either. Adding the two groups together, between $4 \%$ and $6 \%$ of men had ever had a same-sex partner in each cohort (Table 5); by contrast, for women this was $10.5 \%$ in the first cohort and $21.2 \%$ in the last (Table 3). The percent of men identifying as gay did not rise, estimated at $2.8 \%, 1.4 \%, 1.6 \%$, and $1.7 \%$ respectively in the four cohorts (Table 5).

\footnotetext{
${ }^{6}$ There are no significant differences in cohort coefficients between whites and blacks, U.S.-born Hispanics, or Hispanic immigrants on sex with other and same-sex partners ever, sex with only same-sex partners ever, or bis exual identity. The only exception for the outcomes in Table 4 is that U.S.-born Hispanics had a significant increase in identifying as gay the last compared to first cohort; no such increase was present for whites, and the differences between the two group's coefficients for the last cohort are significantly different.
} 
Men's bisexual identity did rise from $1.3 \%$ to $2.4 \%$ (Table 5) but this is not significant

(Table 4). Thus, the clear conclusion is that things changed for women, but not for men, and that by the most recent cohort a much higher proportion of women than men had had sex with both sexes, and claimed a bisexual identity. ${ }^{7}$

\section{DISCUSSION AND CONCLUSION}

We have shown a steady increase across cohorts in women's experience with same-sex partners. The upward trend is present for women having had sex only with women, as well as having sex with both sexes. The proportion of women identifying as bisexual and reporting bisexual attraction has also grown. These upward trends are no less steep among blacks, U.S.-born Hispanics, and Hispanic immigrants than among whites; indeed, for some outcomes increases are steeper for minority groups. Hispanic immigrants differ from other groups of women in being less likely to identify as something other than heterosexual or to have had sex with a same-sex partner; their levels are lower, but their upward trends are typically not significantly different. The upward trends were also largely the same across socioeconomic background groups (measured by mother's education).

By contrast, there is no apparent trend in having only same-sex sexual partners, or partners of both sexes, for men. Nor is there an increase in the proportion of men who identify as gay or bisexual, or report such attraction. For the most part, these "non-trends"

\footnotetext{
7 This conclusion could be challenged under some assumptions about under-reporting. We might think that due to the greater stigma for men than women of gay sex, men would under-report more. If the gender gap in under-reporting remained constant, but men always under-reported more, then we might be overestimating the gender gap in behavior and identities, but our estimates of trends in behavior, although not levels, should be accurate. Another possibility is that women's under-reporting decreased but their behavior did not change; this could possibly yield an increase for women but not men like the one we observe. However, we doubt that the more than doubling of having had a same-sex partner and of bisexual identity was all just a change in reporting.
} 
among men are not significantly different for whites than for blacks, U.S.-born Hispanics, or Hispanic immigrants, nor do they differ across groups of men defined by their mother's education.

A limitation of our analysis is its inability to address how sexual experiences and identities that are not exclusively heterosexual evolve across the life cycle in recent cohorts among whom they are most common. The NSFG data include no one more than 45 years of age and contain only a limited range of cohorts. Because of this, for example, we were unable to see how many of the women in recent cohorts who had sex with both sexes in their early years continued to do so in their $30 \mathrm{~s}$, 40s, or later, or whether most of them transitioned to long-term relationships with either a man or a woman. We hope that future work will explore this.

Another limitation of our analys is is that our data are not rich enough to allow us to test various possible explanations of the cohort trends that we find. What we can offer is a speculative explanation that comports with the central fact shown by our analysisthat movement away from exclusively heterosexual behavior and identity has occurred for women, not men. Our speculation is that two factors each facilitated such change across cohorts of women: the gender revolution and increased acceptances of gay rights. One prominent message of the gender revolution was that it is all right for women to do things only men could previously do. This increased the sense that it was permissible for women to engage in sex with women, even though doing so is still a violation of traditional gender conformity. Increased tolerance for gay rights furthered the sense of permission. 
One might have thought that the same two factors, greater acceptance of gay rights and greater acceptance of nonconforming gender expressions, would have furthered acceptance of men's same-sex relationships in a parallel fashion. While some feminists urged an acceptance of men doing things seen as feminine, and a revalorization of traditionally feminine activities, this was certainly not the message the average person received from the gender revolution, which mostly involved women changing by moving into traditionally male positions and styles. Thus, we speculate that the continued devaluation of the feminine, combined with the fact that same-sex relationships were still seen as gender-bending, meant that engaging in them entailed losing status for men more than it did for women. Therefore, women interested in sex with same-sex partners felt freer than men to engage in such behavior and even to identify as bisexual.

Of course, some men and women have always expressed their same-sex desire, despite stigma, and we do not want to understate the social costs women still experience for departures from exclusive heterosexuality (Mishel 2016). Nonetheless, our conjecture is that changes in norms about gender and heterosexism intersected in a way that provided more of an opening for women than men to have same-sex sexual relations. Whether or not this is the correct explanation, we have shown that women have exhibited much more increase than men across cohorts in reported sex with same-sex partners and in bisexual identity. 


\section{APPENDIX: SENSITIVITY TESTS}

We undertook several sensitivity tests to examine the robustness of our conclusions. One sensitivity test specified cohort linearly instead of with a series of indicator variables. A significant positive coefficient for the linear effect of cohort was found where our main analyses using indicator variables found a significant difference between the first and last cohort; thus, the two analyses agree on which outcomes showed cohort change.

A second sensitivity test used multinomial logistic regressions (MNL) rather than the separate logistic regressions for each outcome described above. Instead of Models 1 and 2, we estimated one MNL with the two competing choices: a) sex with same- and other-sex partners and b) sex with only same-sex partners, each relative to a reference including those who had no or only other-sex partners. (Coefficients cannot be estimated if we make those who have never had sex the reference category and add having othersex partners only as a competing choice, because never having had sex is rare at most ages.) Analogously, instead of Models 3 and 4, we estimated one multinomial logistic regression with the competing options of bisexual identity and gay identity, relative to a reference of heterosexual. These MNL results yield substantive conclusions unchanged from those reported above; however they cannot be estimated separately for whites, blacks, U.S.-born Hispanics, and Hispanic immigrants because of small sample size in some of these groups.

A final sensitivity test addressed the fact that the response options respondents were offered when asked about their sexual orientation included "something else" until midway in 2008 , but not thereafter. In our main analyses predicting gay or bisexual 
identities, respectively, those who said "something else" were classified in the reference category along with heterosexuals. In the sensitivity test, we remove them from the analysis. Substantive conclusions remain unchanged. 


\section{REFERENCES}

Anderson, John E. and R. Stall. 2002. "Increased Reporting of Male-to-Male Sexual Activity in a National Survey." Sexually Transmitted Diseases 29:643-46.

Bell, Andrew, and Kelvyn Jones. 2014. "Another 'futile quest'? A simulation study of Yang and Land's hierarchical age-period-cohort model." Demographic Research 30(11): 33360.

Betts, Peter. 2009. "Developing Survey Questions on Sexual Identity: Cognitive/In-Depth Interviews." Office for National Statistics.

Brown, Eliza and Paula England. February 29, 2016. "Sexual Orientation versus Behavior Different for Men and Women?" Contexts, Retrieved July 2016. (https://contexts.org/blog/sexual-orientation- versus-behavior-different-for-men-andwomen/).

Butler, Amy. 2005. "Gender Differences in the Prevalence of Same-Sex Sexual Partnering: 1988-2002." Social Forces 84 (1): 421-449.

Copen, Casey E., Anjani Chandra, Isa Marie Febo-Vazquez. 2016. "Sexual Behavior, Sexual Attraction, and Sexual Orientation Among Adults Ages 18-44 in the United States: Data from the 2011-2013 National Survey of Family Growth." National Health Statistics Reports (88):1-14.

Dahlhamer James M., Adena M. Galinsky, Sarah S. Joestl, and Brian W. Ward. 2014. "Sexual Orientation in the 2013 National Health Interview Survey: A Quality Assessment." Vital Health Statistics 2(169).

Ellison, Gavin and Briony Gunstone. 2009. "Sexual Orientation Explored: A Study of Identity, Attraction, Behaviour and Attitudes in 2009." YouGov, Equality and Human Rights Commission Research Report 35.

England, Paula. 2010. "The Gender Revolution: Uneven and Stalled." Gender \& Society 24(2): 149-166.

England, Paula. 2016. "Sometimes the Social Becomes Personal: Gender, Class, and Sexualities." American Sociological Review 81(1): 4-28.

Hamilton, Laura. 2007. "Trading on Heterosexuality: College Women's Gender Strategies and Homophobia." Gender \& Society 21: 145-72.

Johnson, Anne M., Catherine H. Mercer, Bob Erens, Andrew J. Copas, Sally McManus, Kaye Wellings, Kevin A. Fenton. 2001. "Sexual Behavior in Britain: Partnerships, Practices, and HIV Risk Behaviours." Lancet 358: 1835-1842.

Mishel, Emma. 2016. "Discrimination against Queer Women in the U.S. Workforce: A Résumé Audit Study." Socius: Sociological Research for a Dynamic World. 2: 1-13.

Pascoe, C.J. 2007. Dude You're a Fag: Masculinity and Sexuality in High School. Los Angeles, CA: University of California Press.

Rupp, Leila, Verta Taylor, Shiri Regev-Messalem, Alison Fogarty, and Paula England. 2014. "Queer Women in the Hookup Scene: Beyond the Closet?" Gender \& Society 28: 212235.

Turner, Charles F., Maria A. Villarroel, James R. Chromy, Elizabeth Eggleston and Susan M. Rogers. 2005. "Trends: Same-Gender Sex among U.S. Adults: Trends across the Twentieth Century and during the 1990s." The Public Opinion Quarterly 69(3): 439-462. 
Twenge, Jean M., Ryne A. Sherman, and Brooke E. Wells. 2016. "Changes in American Adults' Reported Same-Sex Sexual Experiences and Attitudes, 1973-2014.” Archives of Sexual Behavior DOI 10.1007/S10508-01-0769-4.

Villarroel, Maria A. et al. 2006. "Same-Gender Sex in the United States Impact of T-Acasi on Prevalence Estimates." Public Opinion Quarterly 70(2):166-96.

Yang, Yang, and Kenneth C. Land. 2013. Age-period-cohort Analysis: New Models, Methods, and Empirical Applications. Boca Raton, FL: CRC Press. 


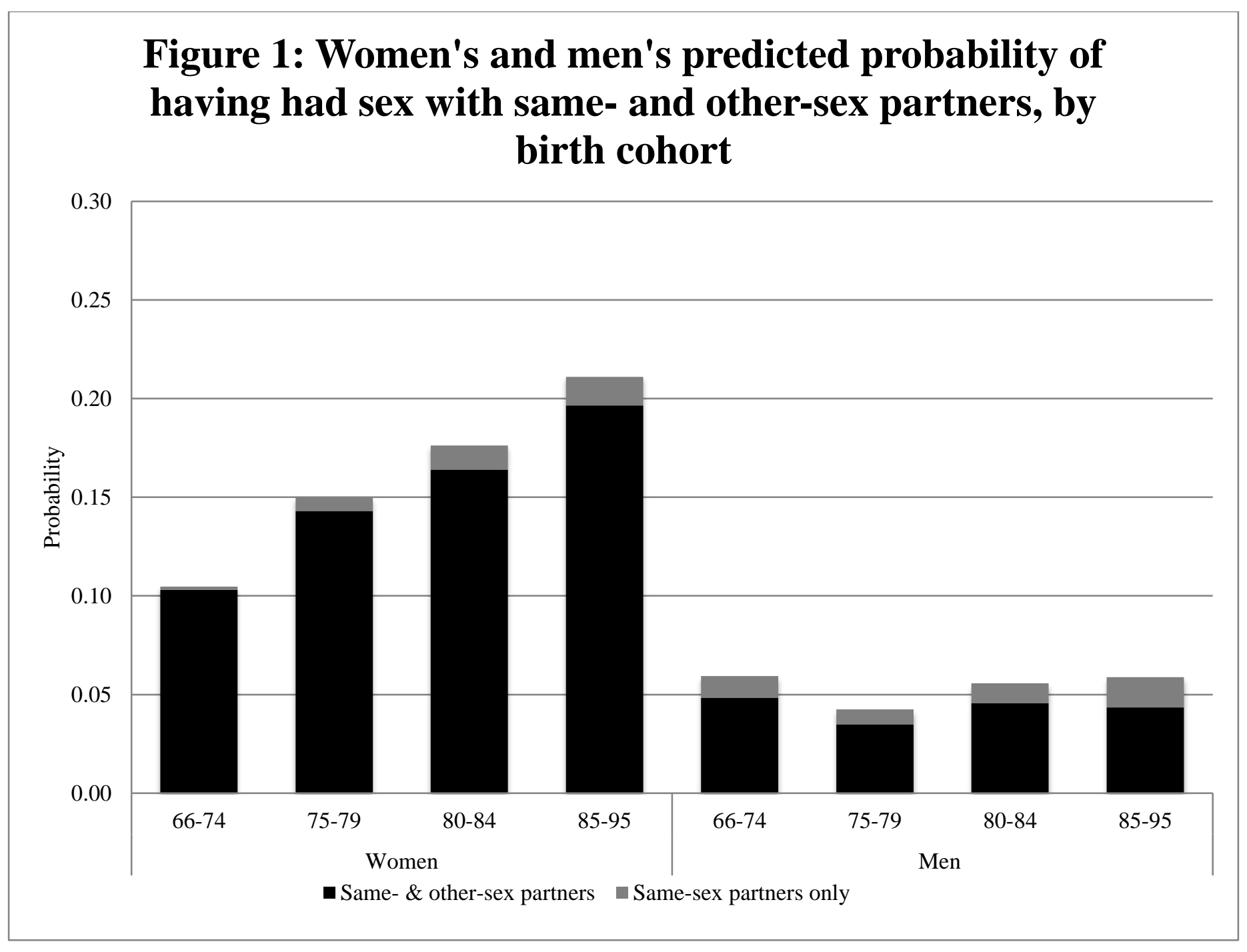




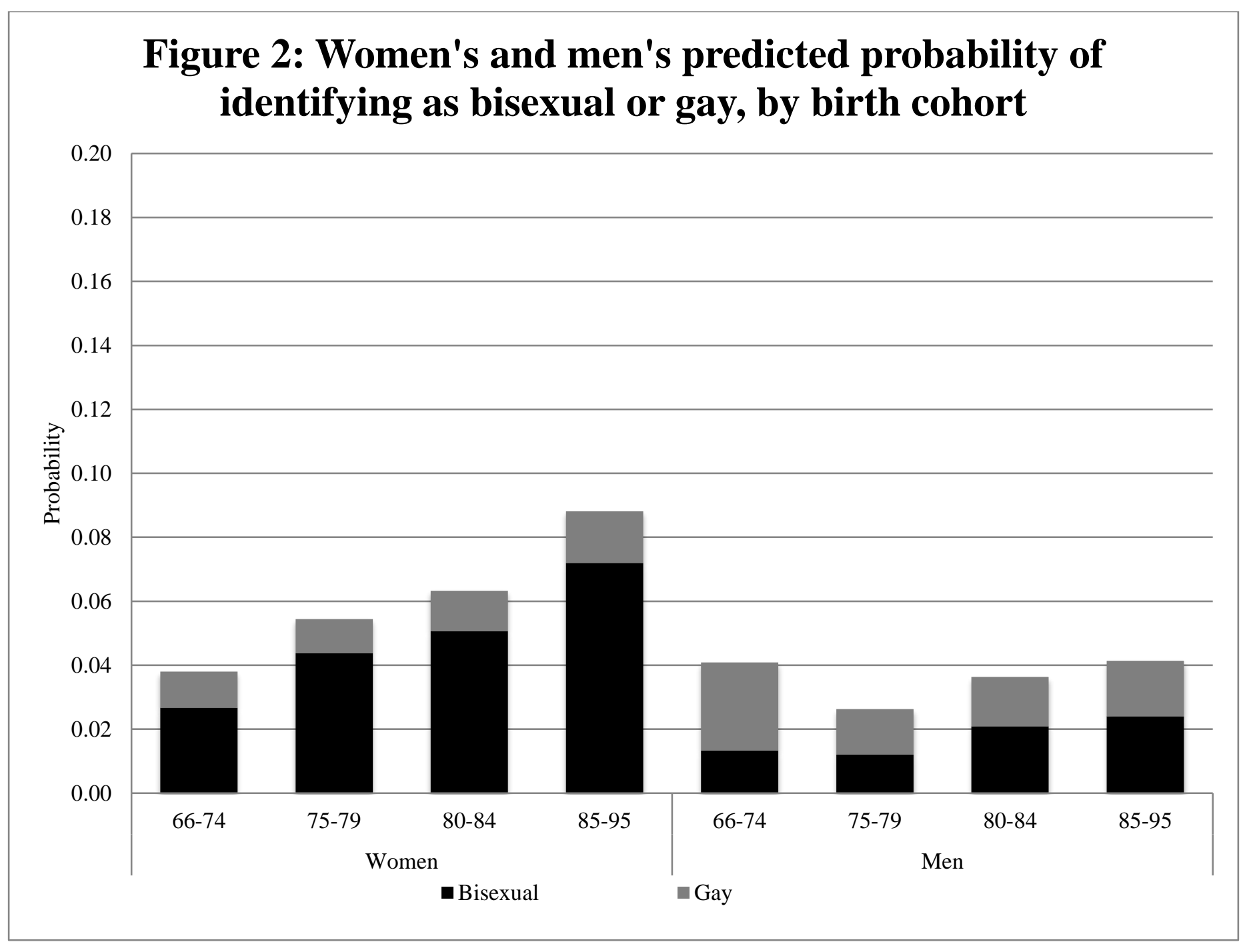




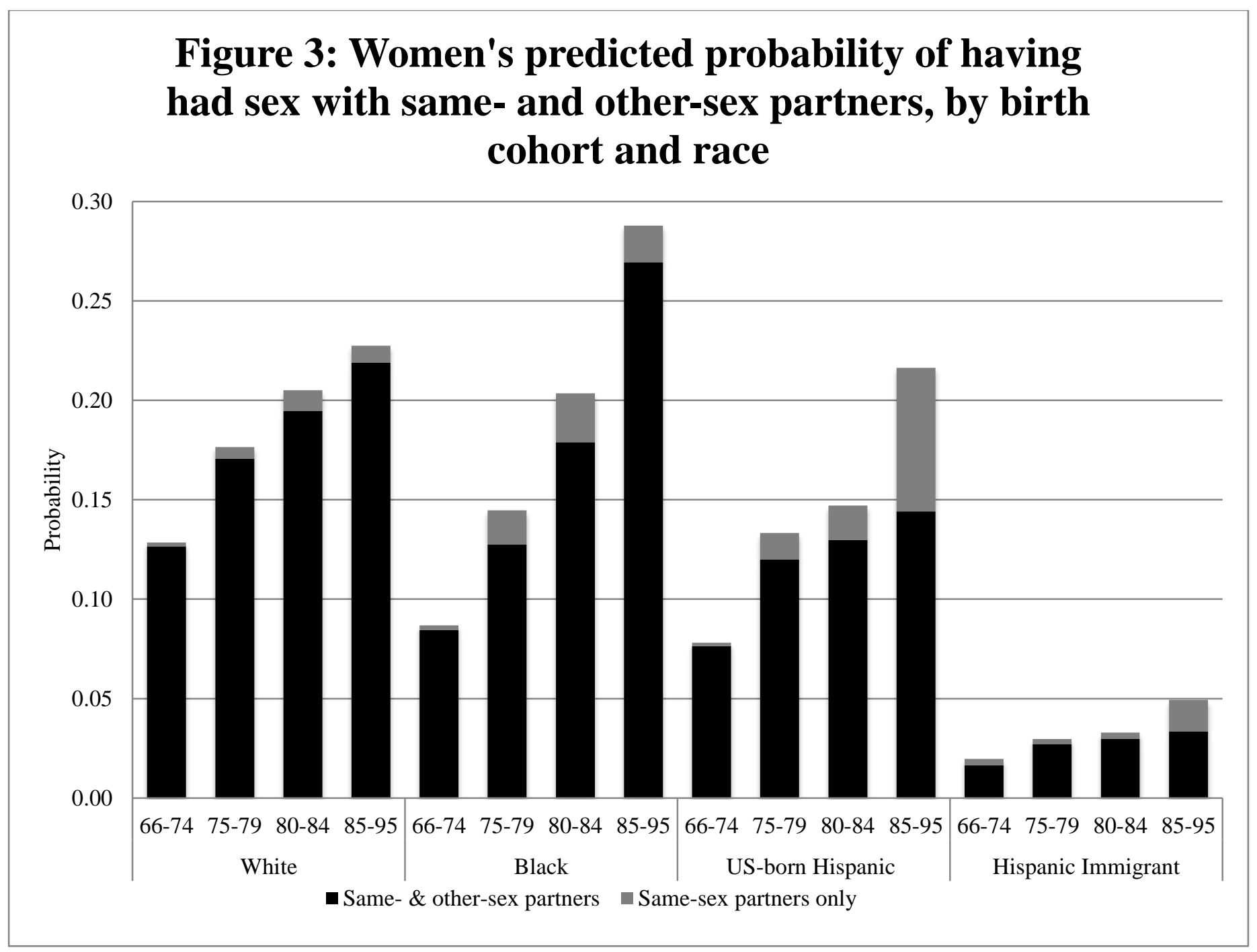




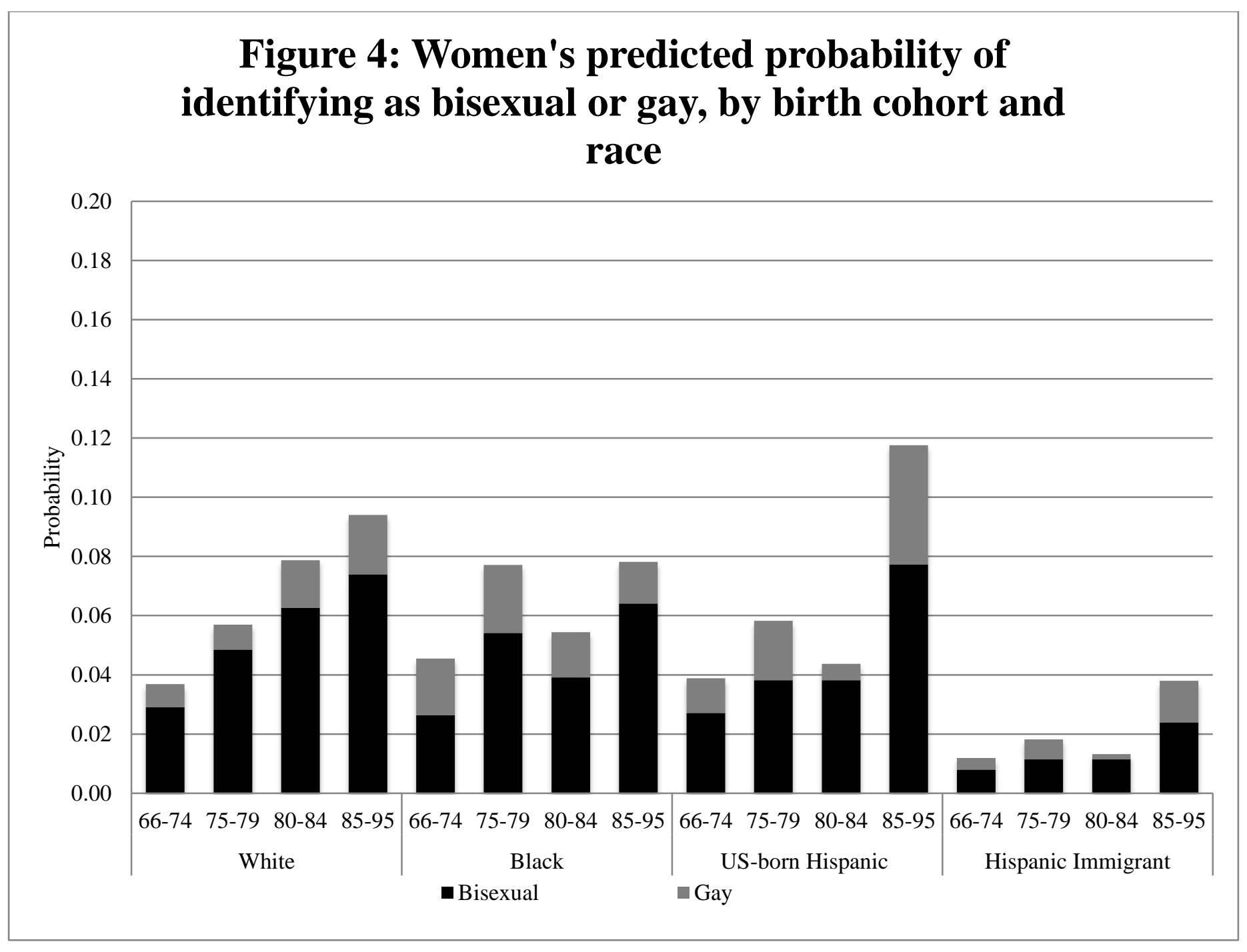




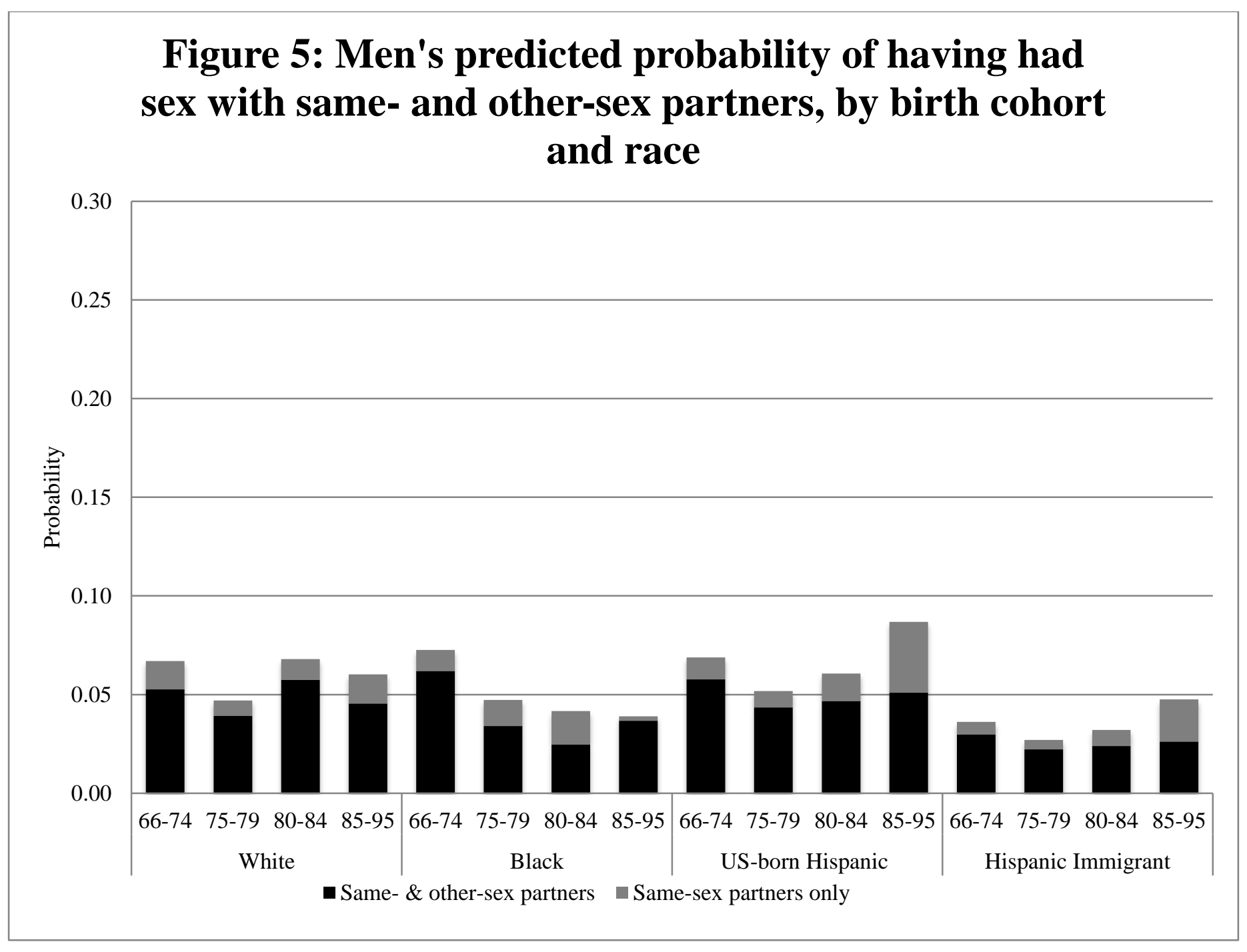




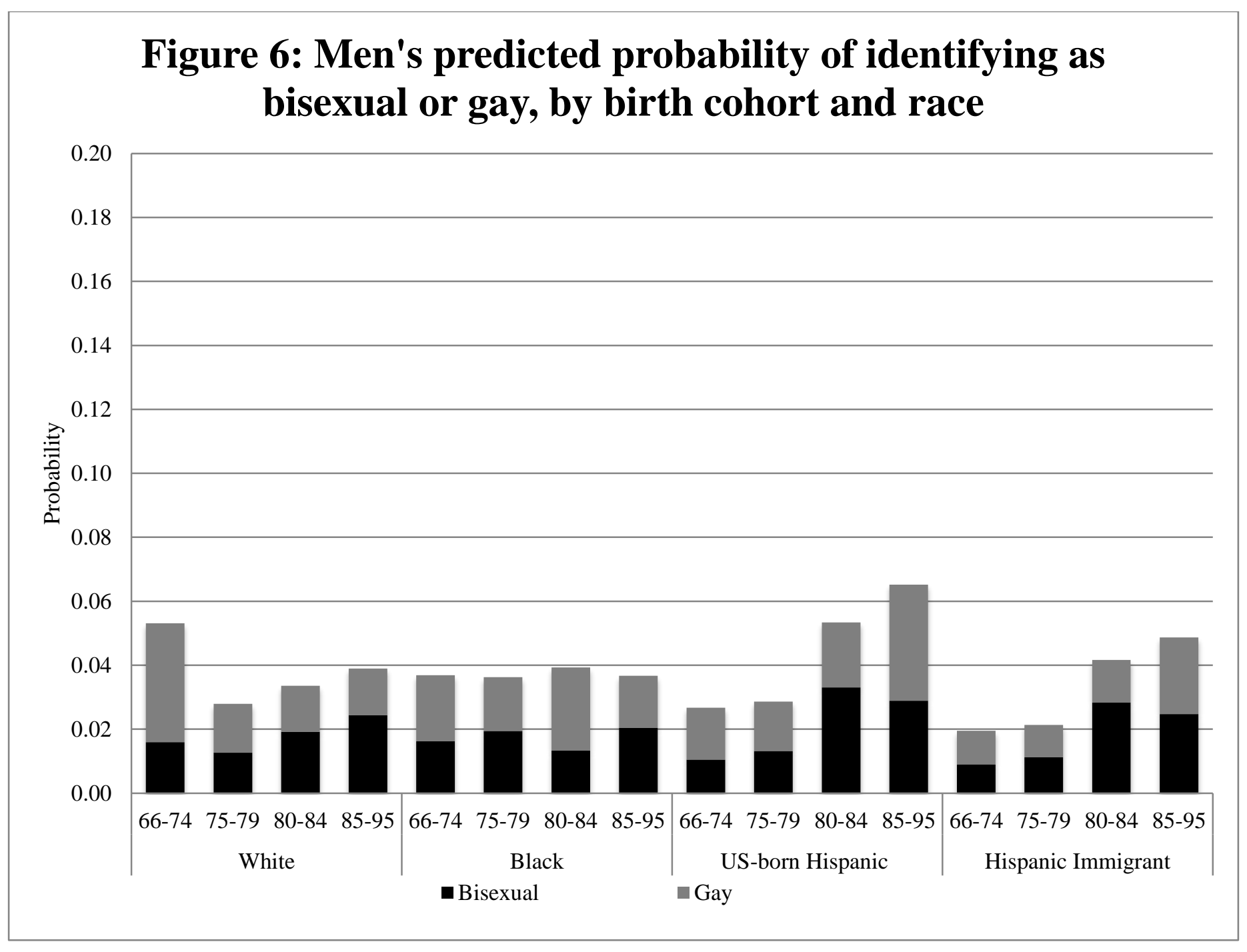




\begin{tabular}{|c|c|c|}
\hline \multicolumn{3}{|c|}{ Table 1: Means by Gender } \\
\hline & Women & Men \\
\hline \multicolumn{3}{|l|}{ Sexual Behavior } \\
\hline $\begin{array}{l}\text { Same- and other-sex } \\
\text { partners ever }\end{array}$ & 0.136 & 0.046 \\
\hline $\begin{array}{l}\text { Only same-sex partners } \\
\text { ever }\end{array}$ & 0.006 & 0.011 \\
\hline $\begin{array}{l}\text { Only other-sex partners } \\
\text { ever }\end{array}$ & 0.799 & 0.878 \\
\hline No partners & 0.059 & 0.065 \\
\hline \multicolumn{3}{|l|}{ Sexial Orientation } \\
\hline Bisexual & 0.041 & 0.017 \\
\hline Gay & 0.013 & 0.020 \\
\hline Heterosexual & 0.932 & 0.949 \\
\hline \multicolumn{3}{|l|}{ Cohort } \\
\hline Born 66-74 & 0.357 & 0.359 \\
\hline Born 75-79 & 0.201 & 0.202 \\
\hline Born 80-84 & 0.221 & 0.212 \\
\hline Born $85-95$ & 0.221 & 0.227 \\
\hline \multicolumn{3}{|l|}{ Race, Ethnicity, and Nativity } \\
\hline White (Non-Hispanic) & 0.625 & 0.625 \\
\hline Black (Non-Hispanic) & 0.141 & 0.121 \\
\hline US-born Hispanic & 0.087 & 0.091 \\
\hline Hispanic Immigrant & 0.082 & 0.097 \\
\hline Non-Hispanic Immigrant & 0.070 & 0.068 \\
\hline \multicolumn{3}{|l|}{ Mother's Education } \\
\hline Less Than High School & 0.235 & 0.212 \\
\hline HS/Some College & 0.570 & 0.578 \\
\hline BA or more & 0.195 & 0.210 \\
\hline
\end{tabular}

Note: $\mathrm{N}$ of entire sample $=22,954$ women and 17,452 men; Ns for individual means vary according to missing values for the variable. 
Table 2: Odds Ratios from Four Logistic Regressions Predicting Whether Women:

1) Have Had Male and Female Sexual Partners (Ever),

2) Have Had Only Female Sexual Partners (Ever), 3) Identify as Bisexual, and 4) Identify as Gay

\begin{tabular}{|c|c|c|c|c|}
\hline & (1) & (2) & (3) & (4) \\
\hline \multicolumn{5}{|l|}{ Cohort (ref: 66-74) } \\
\hline \multirow[t]{2}{*}{ Born 75-79 } & $1.467 * *$ & $4.012 * *$ & $1.673 * *$ & 0.944 \\
\hline & {$[0.153]$} & {$[1.860]$} & {$[0.325]$} & {$[0.260]$} \\
\hline \multirow[t]{2}{*}{ Born 80-84 } & $1.733 * *$ & $7.287 * *$ & $1.949 * *$ & 1.120 \\
\hline & {$[0.229]$} & {$[4.847]$} & {$[0.452]$} & {$[0.443]$} \\
\hline \multirow[t]{2}{*}{ Born 85-95 } & $2.178 * *$ & $8.760 * *$ & $2.847^{* *}$ & 1.436 \\
\hline & {$[0.328]$} & {$[5.805]$} & {$[0.721]$} & {$[0.582]$} \\
\hline \multicolumn{5}{|l|}{ Race (ref: White) } \\
\hline \multirow[t]{2}{*}{ Hispanic } & $0.692 * *$ & $2.168+$ & $0.738+$ & 1.205 \\
\hline & {$[0.078]$} & {$[0.862]$} & {$[0.115]$} & {$[0.366]$} \\
\hline \multirow[t]{2}{*}{ Black } & $0.860+$ & 1.380 & $0.800+$ & 1.329 \\
\hline & {$[0.077]$} & {$[0.467]$} & {$[0.108]$} & {$[0.296]$} \\
\hline \multirow[t]{2}{*}{ Other } & $0.609 * *$ & 1.666 & 1.117 & $1.728+$ \\
\hline & {$[0.110]$} & {$[0.821]$} & {$[0.275]$} & {$[0.560]$} \\
\hline \multirow[t]{2}{*}{ Immigrant } & $0.451 * *$ & 1.533 & 0.824 & 0.978 \\
\hline & {$[0.085]$} & {$[0.777]$} & {$[0.189]$} & {$[0.328]$} \\
\hline \multirow[t]{2}{*}{ Hisp x Immigrant } & $0.376^{* *}$ & $0.134^{*}$ & $0.349 * *$ & $0.304^{*}$ \\
\hline & {$[0.107]$} & {$[0.115]$} & {$[0.125]$} & {$[0.148]$} \\
\hline \multicolumn{5}{|c|}{ Mother's Educ. (ref: $<$ HS) } \\
\hline \multirow[t]{2}{*}{ HS/Some College } & 1.124 & 0.810 & $0.744 *$ & $0.671+$ \\
\hline & {$[0.090]$} & {$[0.294]$} & {$[0.106]$} & {$[0.159]$} \\
\hline \multirow[t]{2}{*}{ BA or more } & 1.050 & 1.577 & $0.625 * *$ & 1.009 \\
\hline & {$[0.117]$} & {$[0.577]$} & {$[0.102]$} & {$[0.288]$} \\
\hline $\mathbf{N}$ & 19699 & 18929 & 19577 & 19577 \\
\hline
\end{tabular}

Standard errors in brackets.

Indicator variables for ages 18-45 were also included in all models, but Odds Ratios not shown. 


\begin{tabular}{|c|c|c|c|c|}
\hline & $\begin{array}{c}\text { Cohort } \\
66-74 \\
\end{array}$ & $\begin{array}{c}\text { Cohort } \\
75-79 \\
\end{array}$ & $\begin{array}{c}\text { Cohort } \\
80-84 \\
\end{array}$ & $\begin{array}{c}\text { Cohort } \\
85-95\end{array}$ \\
\hline \multicolumn{5}{|l|}{ Sexual Behavior } \\
\hline $\begin{array}{l}\text { Same- and other- } \\
\text { sex partners ever }\end{array}$ & 0.103 & 0.143 & 0.164 & $0.197^{*}$ \\
\hline $\begin{array}{l}\text { Only same-sex } \\
\text { partners ever }\end{array}$ & 0.002 & 0.007 & 0.012 & $0.015^{*}$ \\
\hline $\begin{array}{l}\text { Same- and other- } \\
\text { sex partners in past } \\
\text { year }^{1}\end{array}$ & 0.028 & 0.030 & 0.037 & 0.038 \\
\hline $\begin{array}{l}\text { Only same-sex } \\
\text { partners in past } \\
\text { year }^{1}\end{array}$ & 0.009 & 0.014 & 0.019 & 0.020 \\
\hline \multicolumn{5}{|c|}{ Sexial Orientation (Identity) } \\
\hline Bisexual & 0.027 & 0.044 & 0.051 & $0.072 *$ \\
\hline Gay & 0.011 & 0.011 & 0.013 & 0.016 \\
\hline \multicolumn{5}{|l|}{ Sexial Attraction } \\
\hline Bisexual $^{1}$ & 0.138 & 0.160 & 0.175 & $0.195^{*}$ \\
\hline Gay $^{1}$ & 0.004 & 0.006 & 0.011 & $0.011+$ \\
\hline
\end{tabular}

Note: Predicted probabilities are calculated from logistic regression models in Table 2, or not shown, using an average marginal effects approach to adjust for covariates.

${ }^{1}$ These predicted probabilities are from logistic regression models not shown, the same as those in Table 2, but changing the dependent variable.

* The last cohort is significantly higher than the first; $p<.05,2$-tailed test.

+ The last cohort is significantly higher than the first; .10>p $\geq .05$. 
Table 4: Odds Ratios from Four Logistic Regressions Predicting Whether Men:

1) Have Had Male and Female Sexual Partners (Ever), 2) Have Had Only Male Sexual Partners (Ever), 3) Identify as Bisexual, and 4) Identify as Gay

\begin{tabular}{|c|c|c|c|c|}
\hline & (1) & (2) & (3) & (4) \\
\hline \multicolumn{5}{|l|}{ Cohort (ref: 66-74) } \\
\hline \multirow[t]{2}{*}{ Born 75-79 } & $0.711+$ & 0.683 & 0.900 & $0.508 *$ \\
\hline & {$[0.143]$} & {$[0.262]$} & {$[0.353]$} & {$[0.161]$} \\
\hline \multirow[t]{2}{*}{ Born 80-84 } & 0.942 & 0.908 & 1.584 & 0.554 \\
\hline & {$[0.254]$} & {$[0.413]$} & [0.799] & {$[0.220]$} \\
\hline \multirow[t]{2}{*}{ Born 85-95 } & 0.895 & 1.398 & 1.828 & 0.625 \\
\hline & [0.287] & [0.707] & [1.002] & {$[0.271]$} \\
\hline \multicolumn{5}{|l|}{ Race (ref: White) } \\
\hline \multirow[t]{2}{*}{ Hispanic } & 1.103 & 1.556 & 0.970 & 1.225 \\
\hline & {$[0.232]$} & {$[0.530]$} & {$[0.290]$} & {$[0.341]$} \\
\hline \multirow[t]{2}{*}{ Black } & 0.825 & $0.538 *$ & 0.829 & 0.809 \\
\hline & {$[0.128]$} & {$[0.158]$} & [0.187] & {$[0.148]$} \\
\hline \multirow[t]{2}{*}{ Other } & $0.444 * *$ & $2.207 *$ & 1.297 & 1.065 \\
\hline & {$[0.111]$} & {$[0.857]$} & {$[0.391]$} & {$[0.364]$} \\
\hline \multirow[t]{2}{*}{ Immigrant } & 0.589 & 0.526 & $0.337^{*}$ & 0.735 \\
\hline & {$[0.208]$} & {$[0.240]$} & {$[0.150]$} & {$[0.229]$} \\
\hline \multirow[t]{2}{*}{ Hisp x Immigrant } & 0.756 & 0.797 & 1.926 & 0.615 \\
\hline & {$[0.326]$} & {$[0.551]$} & [1.148] & {$[0.294]$} \\
\hline \multicolumn{5}{|c|}{ Mother's Educ. (ref: < HS) } \\
\hline \multirow[t]{2}{*}{ HS/Some College } & 1.095 & $2.562 * *$ & 0.686 & $1.541+$ \\
\hline & {$[0.188]$} & {$[0.867]$} & [0.199] & {$[0.342]$} \\
\hline \multirow[t]{2}{*}{ BA or more } & 1.092 & 1.780 & 0.842 & 1.092 \\
\hline & {$[0.258]$} & {$[0.677]$} & {$[0.283]$} & {$[0.304]$} \\
\hline $\mathbf{N}$ & 15242 & 15238 & 15201 & 15201 \\
\hline
\end{tabular}

$+\mathrm{p}<.10 \quad * \mathrm{p}<0.05 \quad * * \mathrm{p}<0.01$

Standard errors in brackets.

Indicator variables for ages 18-45 were also included in all models, but Odds Ratios not shown. 


\begin{tabular}{|c|c|c|c|c|}
\hline & $\begin{array}{c}\text { Cohort } \\
66-74\end{array}$ & $\begin{array}{c}\text { Cohort } \\
75-79\end{array}$ & $\begin{array}{c}\text { Cohort } \\
80-84\end{array}$ & $\begin{array}{l}\text { Cohort } \\
85-95\end{array}$ \\
\hline \multicolumn{5}{|l|}{ Sexual Behavior } \\
\hline $\begin{array}{l}\text { Same- and other- } \\
\text { sex partners ever }\end{array}$ & 0.048 & 0.035 & 0.046 & 0.043 \\
\hline $\begin{array}{l}\text { Only same-sex } \\
\text { partners ever }\end{array}$ & 0.011 & 0.008 & 0.010 & 0.015 \\
\hline $\begin{array}{l}\text { Same- and other- } \\
\text { sex partners in past } \\
\text { year }^{1}\end{array}$ & 0.007 & 0.009 & 0.010 & 0.014 \\
\hline $\begin{array}{l}\text { Only same-sex } \\
\text { partners in past } \\
\text { year }^{1}\end{array}$ & 0.020 & 0.011 & 0.016 & 0.024 \\
\hline \multicolumn{5}{|c|}{ Sexial Orientation (Identity) } \\
\hline Bisexual & 0.013 & 0.012 & 0.021 & 0.024 \\
\hline Gay & 0.028 & 0.014 & 0.016 & 0.017 \\
\hline \multicolumn{5}{|l|}{ Sexial Attraction } \\
\hline Bisexual $^{1}$ & 0.061 & 0.045 & 0.053 & 0.058 \\
\hline Gay $^{1}$ & 0.019 & 0.007 & 0.009 & 0.018 \\
\hline
\end{tabular}

Note: Predicted probabilities are calculated from logistic regression models in Table 4, or not shown, using an average marginal effects approach to adjust for covariates. None of the predicted probabilities for the last cohort is significantly higher than for the first cohort.

${ }^{1}$ These predicted probabilities are from logistic regression models not shown, the same as those in Table 4, but changing the dependent variable. 